\title{
EVALUATION OF LONG-TERM RESULTS OF TWO DIFFERENT CALCIUM SILICATE BASED MATERIALS IN PRIMARY MOLAR TEETH VITAL PULPOTOMIES: AN INVIVO STUDY
}

\section{ABSTRACT}

Objectives: Pulpotomy is one of the pulp therapy for cariously exposed pulps in primary molar teeth. There are several materials that allows regeneration of the residual pulp. The purpose of this study was to evaluate the efficacy of two different calcium silicate based materials (ProRoot MTA, BIOfactor MTA) in primary molar teeth vital pulpotomies.

Materials and Methods: A total of 12 children (24 human mandibulary primary second molar teeth) aged between 6 and 9 years were selected in this randomized clinical study. The patients were randomly assigned to receive the pulpotomy medicaments. All pulpotomized teeth were restored with stainless steel crowns and evaluated clinically and radiologically at 1, 3, 6 and 12 months. Statistical analysis using chi-square test was performed to determine the significant differences between two materials.

Results: Neither clinical nor radiographical differences were seen in 1st, 3rd and 6th months but in 12th month ProRoot MTA showed statistically better results in clinical evaluation $(\mathrm{p}=0.047)$.

Conclusions: Both two calcium silicate based materials showed similar clinical and radiographical results by the end of 6th month but ProRoot MTA showed better results at the end of 12 th month.

Keywords: ProRoot MTA, BIOfactor MTA, pulpotomy.

\author{
*Fatih OZNURHAN ${ }^{1}$ \\ Mevlut KAYABAŞI ${ }^{1}$ \\ Büşra KESKÜŞ ${ }^{1}$
}

ORCID IDs of the authors: F.Ö. $0000-0002-7797-0932$ M.K. $0000-0002-8138-4346$

B.K. $0000-0002-6966-8442$ 


\section{INTRODUCTION}

At the present time, in spite of the reduction of dental caries prevalence in different parts of the world, this disease continues to be one of the major public health problems affecting many children and adolescents in its most severe form. ${ }^{1-}$

3 Primary teeth are important because of their function as a space maintainer for the permanent teeth below, stimulating the vertical development of the jaws with chewing movements, contributing to the nutrition, growth and development of the child, phonation and aesthetic functions. Therefore, preservation of the dental arch until the time of physiological fall is necessary in terms of permanent dentition and jaw development. $^{4,5}$ If they leave untreated or extracted; decreased chewing function, loss of space, malocclusion formation, speech disorders, psychological disorders, surgical trauma, atypical language habits may occur. In order to avoid such problems, it is necessary to maintain the function of the teeth at the dental arch till they exfoliate. ${ }^{6}$

The structural and histological differences between the pulps of primary teeth and the pulses of permanent teeth affect the primary teeth pulp response to carious lesions and pulp therapies. ${ }^{7}$ Pulpotomy is one of the most common therapy in primary teeth. Pulpotomy therapy is defined as the process of removing the teeth of the infected tooth and removing the normal root pulp of the normally infected root pulp and maintaining the vitality and function of the tooth with a bactericidal agent. Clinicians have used different pulpotomy agents and methods, such as formocresol, a calcium silicate-based bioactive material, Ankaferd blood stopper, enamel matrix derivative, calcium hydroxide, zinc oxide and eugenol, sodium hypochlorite, glutaraldehyde, ferric sulfate, Portland cement, mineral trioxide aggregate (MTA), calcium hydroxide and iodoform, electrosurgery, and laser therapies. ${ }^{8,} 9$ The ideal agent or method for amputation treatment of primary teeth has not yet been determined. ${ }^{10}$

MTA has been recognized for its high success rate in clinical and radiological examinations in conservative pulp therapies.
However, the MTA has a long curing time and requires moisture during hardening, its manipulation is difficult. Therefore, researchers continue to research to improve the physical properties of materials. ${ }^{10}$

A new type of MTA, BIOfactor MTA (Imicryl Dental, Konya, Turkey), has recently been introduced on the market to be used for pulp capping, pulpotomies, apexification, root end filling, apical plug procedures and root perforation repairs. This cement can be prepared in a flowing or thickness, based on the treatment type. The manufacturer claims that BIOfactor MTA has a shorter setting time, finer powder for faster hydration, easier handling properties, stronger sealing, and that it does not cause tooth discoloration. Moreover, BIOfactor MTA seems to be a lower costing product. There is no difference between materials and methods during the use of both materials. Depending on the content of the materials, the mixing times vary. ${ }^{10}$

The new material BIOfactor MTA had never been tested in primary molar teeth with a long time period. Therefore, the aim of this study is to compare and evaluate the long-term results of the primary teeth vital amputations of two different calcium-silicate-based materials (ProRoot MTA and BIOfactor MTA) used in routine clinical practice.

\section{MATERIALS AND METHODS}

Ethical approval was obtained from Sivas Cumhuriyet University Clinical Research Ethics Committee (2017-07/35) and the study was conducted at the Faculty of Dentistry, Department of Pediatric Dentistry, Sivas Cumhuriyet University. The clinical procedure, associated risks, and benefits were fully explained to the parents of the participants and written consent to participate was obtained before the procedure.

\section{Sample Size Calculation}

Sample size was performed under the assumption of studies that have resemble to our study., 11,12 Accepting $\alpha=0.05, \beta=0.10,(1-\beta)=0.90$ a total of 24 subjects are necessary (12 in ProRoot MTA group and 12 in BIOfactor MTA group). The power of test was found 0,90169 . The study was 
performed on 24 mandibulary, carious primary second molar teeth of 12 patients ( 7 girls, 5 boy), aged between 6 and 9 years (in the mind of starting root resorption age according to Logan and Kronfeld $)^{13}$ assigned into two groups that included ProRoot MTA and, BIOfactor MTA allocating 12 teeth in each group using simple lottery method.

Intra- and extraoral examinations of patients were performed before the treatment and their initial radiologic examinations were performed.

Patients who had no disease, such as congenital or rheumatic heart disease, leukemia, allergic reactions to substances, such as local anesthetics and latex, who did not require general anesthesia and sedation, and who had good individual and family cooperation were included in the study.

The teeth requiring pulpotomy were selected based on the inclusion criteria: deep cavity lesions that exposed vital pulp during the removal of caries; no history of spontaneous or nocturnal pain; absence of clinical symptoms such as swelling, fistula, tenderness of the percussion or palpation, pathologic mobility; those in which hemostasis was achieved within 5 minutes during clinical procedure; and the presence of two-thirds of the root length radiographically. No Table 1. Compositions of MTAs

\begin{tabular}{ll}
\hline Material & Composition \\
\hline & Liquid: Demineralised water, 1-5\% hydrosoluble polymer for gelling \\
effect and reology. & Powder: Tricalcium silicate,dicalcium silicate and tricalcium aluminate \\
BIOfactor MTA & calcium sulphate hemihydrate.Ytterbium Oxide for radiopacity. There is \\
& no Bizmuth due do discoloration of tooth \\
& Liquid: Distilled water \\
ProRoot MTA & Powder: Calcium silicate, calcium sulfate, tricalcium aluminate, calcium \\
& oxide, iron oxide, and bismuth oxide \\
\hline
\end{tabular}

MTA was prepared according to the manufacturer's instructions by mixing MTA powder with distilled water in a 3:1 ratio and pulp stumps were covered. The MTA condensed lightly with a moistened cotton pellet. Resinmodified glass ionomer cement (Vitrebond 3M ESPE, Seefeld, Germany) was placed to fill the pulp chamber. The teeth were restored with stainless steel crowns (3M ESPE, Dental radiographic evidence of pulp degeneration, such as internal or external root resorption, furcal radiolucency, interradicular or periapical bone destruction, or pulp stones.

The 24 teeth that were considered according to the abovementioned criteria were randomized into two study groups. In the first group, ProRoot MTA pulpotomy was performed on 12 teeth and BIOFactor MTA pulpotomy was performed on the rest in the second group.

\section{Treatment Procedures}

After performing topical anesthesia by lidocaine spray, regional anesthesia was administered by Maxicaine D-S (Maxicaine, Vem İlaç, Ankara, Turkey). All cavity lesions were removed and an access cavity was prepared under the isolation of rubber dam. A low-speed sterile round bur (No.12, No.18) and excavator were used for removing coronal pulp. Sterile cotton pellets moistened with sterile saline were placed over the pulp stumps and was applied with a light pressure for 5 minutes. All pulpotomy procedures were performed by one pediatric dentist.

After the bleeding control is achieved, one of the treated pulps of the teeth will be applied to the ProRoot MTA (Dentsply Tulsa Dental, Tulsa, OK, USA) and the other to the BIOfactor MTA (Imicryl Dental, Konya, Turkey)(Table 1).

Products, St. Paul, MN, USA) and cemented with glass ionomer cement (Meron ${ }^{\circledR}$ Voco, Cuxhaven, Germany). The reason we cover with stainless steel crowns is to prevent possible microspheres.

Evaluation of Pulpotomy Treatment and Stainless Steel Crown (SSC) Application

After applying SSC, the first radiographs were taken and the patients were recalled for clinical and radiographic evaluation after 1, 3, 6 and 12 
months. Clinical and radiological evaluations were performed independently by two experienced pediatric dentists. The teeth were considered successful if they had no symptoms of palpation-percussion sensitivity, spontaneous pain, hot-cold sensitivity, presence of fistula as welling, pathologic mobility, internal-external resorption, periapical/interradicular bone destruction, disintegration of the lamina dura, enlargement of the periodontal space, and radiological calcific metamorphosis.

\section{Statistical evaluation}

The data obtained from our study were loaded into SPSS (22.0) program and chi-square test was performed to determine the significant differences between two materials. A $P$ value $<0.05$ was considered statistically significant.

\section{RESULTS}

12 children were participated to this study and $58.33 \%$ were girls $(n=7)$, and $41.67 \%$ were boys $(\mathrm{n}=5)$.

Radiological and clinical evaluation of ProRoot MTA and BIOfactor MTA (1-12 months) were shown on Table 2.

Table 2. Radiological and clinical evaluation of ProRoot MTA and BIOfactor MTA (1-12 months)

\begin{tabular}{|c|c|c|c|c|c|c|}
\hline & & \multicolumn{2}{|c|}{ Radiographical Evaluation } & \multicolumn{3}{|c|}{ Clinical Evaluation } \\
\hline \multicolumn{2}{|c|}{ Recall Periods/Materials } & Success (n) & Failure (n) & Success (n) & Failure (n) & \\
\hline \multirow[t]{2}{*}{ 1. Month } & ProRoot MTA & 12 & & 12 & & \\
\hline & BIOfactor MTA & 12 & & 12 & & \\
\hline \multirow[t]{3}{*}{ 3. Month } & ProRoot MTA & 11 & 1 & 12 & 0 & \\
\hline & BIOfactor MTA & 9 & 3 & 10 & 2 & \\
\hline & & & $\mathrm{p}=0.295$ & & & $p=0.239$ \\
\hline \multirow[t]{3}{*}{ 6. Month } & ProRoot MTA & 11 & 1 & 12 & 0 & \\
\hline & BIOfactor MTA & 8 & 4 & 9 & 3 & \\
\hline & & & $\mathrm{p}=0.158$ & & & $\mathrm{p}=0.109$ \\
\hline \multirow[t]{3}{*}{ 12. Month } & ProRoot MTA & 10 & 2 & 12 & 0 & \\
\hline & BIOfactor MTA & 7 & 5 & 8 & 4 & \\
\hline & & & $\mathrm{p}=0.185$ & & & $\mathrm{p}=0.047$ \\
\hline
\end{tabular}

There were no significant differences at the end of the $1^{\text {st }}$ month and both two groups showed no failure.

At the end of $3^{\text {rd }}$ month, ProRoot MTA showed 1 radiographical failure and BioFactor MTA showed 3 radiographical and 2 clinical failure but that remained no statistically differences.

ProRoot MTA showed 1 radiographical failure and BioFactor MTA showed 4 radiographical and 3 clinical failure at the end of $6^{\text {th }}$ month and there no significant differences.

At the end of $12^{\text {th }}$ month ProRoot MTA showed 2 radiographical failure and BioFactor MTA showed 5 radiographical and 4 clinical failure and ProRoot MTA showed statistically better results in clinical evaluation ( $\mathrm{p}=0.047$ ).

\section{DISCUSSION}

Pulpotomy is a routine procedure in pediatric dentistry for asymptomatic primary molar teeth that have been exposed with caries. The aim of this procedure is to amputate the infected coronal pulp tissue and cover the vital radicular pulp tissue using an agent such as biocompatible, nonirritating, impermeable and also bioinductive. With the development of materials that have all these properties, the research for pulpotomy agents has expanded. One of these materials that have been used in routine in clinics is MTA. ${ }^{14}$ This clinical trial was conducted to evaluate the effects of the use of two different calcium silicate based materials as ProRoot MTA and BIOfactor MTA as pulpdressing agents during pulpotomies of primary molars.

The manufacturer of BIOfactor MTA claims that the new MTA has easier handling properties, a finer powder for faster hydration, stronger 
sealing and a shorter setting time, and that it does not cause tooth discoloration. Additionally, BIOfactor MTA seems to be a lower costing product. In this present study, we aimed to evaluate as a novel type of calcium-silicate based cements called BIOfactor MTA compared to a well-known and an overworked material as ProRoot MTA on the clinical and radiological success in primary molar pulpotomies. The results of this study showed that there was no statistically significant differences between two MTAs in 1., 3. and 6. Months of follow-up however ProRoot MTA found successful when compared to BIOfactor MTA in 12. Months clinical follow-up.

There are numerous studies have evaluated on the clinical and radiological success of different types of MTA in pulpotomy and showed that all types of MTA had good results. ${ }^{15-20}$ Both MTA Angelus and ProRoot MTA had significantly greater clinical and radiographic success rates compared to calcium hydroxide following pulpotomy in primary molar teeth. ${ }^{21,22}$ No significant difference was found between two different MTAs such as white and gray ProRootMTA as pulpotomy agents in primary teeth. $^{23,24}$ In this study, ProRoot MTA and BIOfactor MTA have also high clinical and radiological success rates.

Celik et $a .^{21}$ evaluated of clinical and radiological success of ProRoot MTA and MTA Angelus and revealed that ProRoot MTA had high clinical (for ProRoot MTA 98\% - for MTA Angelus 96\%) and radiological (for ProRoot MTA 98\% - for MTA Angelus 691) success rate in 24months follow-up despite of there were no statistically significant differences. Our findings are in agreement with this previous research that revealed no statistically significant differences between ProRoot and BIOfactor MTA in first 6 months. However, in 12 months follow-up, ProRoot MTA had statistically significant higher clinical (for ProRoot MTA 100\% - for BIOfactor MTA 66.6\%) and radiological (for ProRoot MTA $83.3 \%$ - for BIOfactor MTA 58.3\%) success rates than BIOfactor MTA $(\mathrm{p}<0.05)$.

There were four clinical failures that all in BIOfactor MTA group. The failures in this present study involved gingival swelling, which has long been considered a clinical failure after a primary molar pulpotomy treatment. ${ }^{17,25,26}$ However, the molars suffering from gingival swelling could cause by lack of oral hygiene and accumulation of dental plaque around the stainless steel crowns or a combination of these two factors. The BIOfactor MTA has some different component like ytterbium oxide, which added in the cement as a radiopacifier agent, unlike ProRoot MTA. This chemical composition differences could cause by changing the cement's penetration into the dentin tubules that due to leakage. The effects of different chemical composition in the calcium silicate-based material on the material's physicochemical properties are unknown. Further studies are required to determine the results of these changings.

There were two radiological failures in ProRoot MTA group which did not shown as a clinical failure finding on the evaluated samples. In this study, these examined primary molars remained asymptomatic during 12 months followup. In BIOfactor MTA group, there were five radiological failures which the same four molars of these radiologically failured five were shown as a clinical failure finding. The inconsistincy of these findings in BIOfactor MTA group could be caused by the decision of the clinical observer's of the study which was the tooth without clinical failure findings could be delayed for extraction. The reasons for radiological failures should be histologically evaluated, which is one of the shortcomings of the study.

One of the limitations of this study is the setting time. Setting time is a crucial factor for these materials. There a lot of study that compared the setting time of calcium silicate based materials, but there is no consensus about the initial time and final curing time. ${ }^{27}$ Long setting times are bringing many problems and researches are trying to overcome with this problem. Haghgoo and Abbasi $^{28}$ declared that when MTA was not condensed evenly, and the ratio of powder to liquid, temperature and air entrapped into the mass, can affect the form of the material 
and these factors may have affected the outcome of our study.

One of the limitations of this study is the small sample size, therefore these results should be done with a large number of participants and with an increased follow-up period.

\section{CONCLUSIONS}

Two calcium silicate based materials showed similar clinical and radiographical results by the end of 6th month but ProRoot MTA showed better results at the end of 12 th month.

\section{ACKNOWLEDGEMENTS}

This work was supported by the Scientific Research Project Fund Cumhuriyet University [grant number DIS-208].

\section{CONFLICT OF INTEREST}

The authors declare that they have no conflict of interest.

\section{REFERENCES}

1. Gimenez T, Bispo BA, Souza DP, Vigano ME, Wanderley MT, Mendes FM, Bonecker M, Braga MM. Does the Decline in Caries Prevalence of Latin American and Caribbean Children Continue in the New Century? Evidence from Systematic Review with Meta-Analysis. PLoS One. 2016;11:1-14.

2. Kassebaum NJ, Smith AGC, Bernabe E, Fleming TD, Reynolds AE, Vos T, Murray CJL, Marcenes W, Collaborators GBDOH. Global, Regional, and National Prevalence, Incidence, and Disability-Adjusted Life Years for Oral Conditions for 195 Countries, 19902015: A Systematic Analysis for the Global Burden of Diseases, Injuries, and Risk Factors. J Dent Res. 2017;96:380-387.

3. Stringhini Junior E, Dos Santos MGC, Oliveira LB, Mercade M. MTA and biodentine for primary teeth pulpotomy: a systematic review and meta-analysis of clinical trials. Clin Oral Investig. 2019;23:1967-1976

4. Caicedo R, Abbott PV, Alongi DJ, Alarcon MY. Clinical, radiographic and histological analysis of the effects of mineral trioxide aggregate used in direct pulp capping and pulpotomies of primary teeth. Aust Dent J. 2006;51:297-305.

5. Godhi B, Sood PB, Sharma A. Effects of mineral trioxide aggregate and formocresol on vital pulp after pulpotomy of primary molars: An in vivo study. Contemp Clin Dent. 2011;2:296-301

6. Misra S, Tahmassebi JF, Brosnan M. Early childhood caries--a review. Dent Update. 2007;34:556564.

7. Smail-Faugeron V, Glenny AM, Courson F, Durieux P, Muller-Bolla M, Fron Chabouis H. Pulp treatment for extensive decay in primary teeth. Cochrane Database Syst Rev. 2018; 5: CD003220.

8. Shafaee H, Alirezaie M, Rangrazi A, Bardideh E. Comparison of the success rate of a bioactive dentin substitute with those of other root restoration materials in pulpotomy of primary teeth: Systematic review and meta-analysis. J Am Dent Assoc. 2019;150:676-688.

9. Carti O, Oznurhan F. Evaluation and comparison of mineral trioxide aggregate and biodentine in primary tooth pulpotomy: Clinical and radiographic study. Niger J Clin Pract. 2017;20:1604-1609.

10. Lin PY, Chen HS, Wang YH, Tu YK. Primary molar pulpotomy: a systematic review and network meta-analysis. J Dent. 2014;42:1060-1077.

11. Cuadros-Fernandez C, Lorente Rodriguez AI, SaezMartinez S, Garcia-Binimelis J, About I, Mercade M. Short-term treatment outcome of pulpotomies in primary molars using mineral trioxide aggregate and Biodentine: a randomized clinical trial. Clin Oral Investig. 2016;20:1639-1645.

12. Gandolfi MG, Siboni F, Polimeni A, Bossù M, Riccitiello F, Rengo S. In vitro screening of the apatiteforming ability, biointeractivity and physical properties of a tricalcium silicate material for endodontics and restorative dentistry. Dentistry Journal. 2013;1:41-60.

13. Logan WH, Kronfeld R. Development of the human jaws and surrounding structures from birth to the age of fifteen years. The Journal of the American Dental Association 1933;20:379-428.

14. Agamy HA, Bakry NS, Mounir MM, Avery DR. Comparison of mineral trioxide aggregate and formocresol as pulp-capping agents in pulpotomized primary teeth. Pediatr Dent. 2004;26:302-309.

15. Ansari G, Ranjpour M. Mineral trioxide aggregate and formocresol pulpotomy of primary teeth: a 2-year follow-up. Int Endod J. 2010; 43(5): 413-418 
16. Farsi N, Alamoudi N, Balto K, Mushayt A. Success of mineral trioxide aggregate in pulpotomized primary molars. J Clin Pediatr Dent. 2005;29:307-311

17. Holan G, Eidelman E, Fuks AB. Long-term evaluation of pulpotomy in primary molars using mineral trioxide aggregate or formocresol. Pediatr Dent. 2005;27:129-136

18. Niranjani K, Prasad MG, Vasa AA, Divya G, Thakur MS, Saujanya K. Clinical Evaluation of Success of Primary Teeth Pulpotomy Using Mineral Trioxide Aggregate((R)), Laser and Biodentine(TM)an In Vivo Study. J Clin Diagn Res. 2015;9:35-37

19. Nowicka A, Lipski M, Parafiniuk M, SporniakTutak K, Lichota D, Kosierkiewicz A, Kaczmarek W, Buczkowska-Radlinska J. Response of human dental pulp capped with biodentine and mineral trioxide aggregate. J Endod. 2013;39:743-747

20. Sonmez D, Sari S, Cetinbas T. A Comparison of four pulpotomy techniques in primary molars: a longterm follow-up. J Endod. 2008;34:950-995

21. Celik B, Atac AS, Cehreli ZC, Uysal S. A randomized trial of mineral trioxide aggregate cements in primary tooth pulpotomies. J Dent Child (Chic). 2013;80:126-132

22.22. Liu H, Zhou Q, Qin M. Mineral trioxide aggregate versus calcium hydroxide for pulpotomy in primary molars. Chin J Dent Res. 2011;14:121-125
23. Cardoso-Silva C, Barberia E, Maroto M, GarciaGodoy F. Clinical study of Mineral Trioxide Aggregate in primary molars. Comparison between Grey and White MTA--a long term follow-up (84 months). J Dent. 2011;39:187-193

24. Frenkel G, Kaufman A, Ashkenazi M. Clinical and radiographic outcomes of pulpotomized primary molars treated with white or gray mineral trioxide aggregate and ferric sulfate--long-term follow-up. J Clin Pediatr Dent. 2012;37:137-141

25. Erdem AP, Guven Y, Balli B, Ilhan B, Sepet E, Ulukapi I, Aktoren O. Success rates of mineral trioxide aggregate, ferric sulfate, and formocresol pulpotomies: a 24-month study. Pediatr Dent. 2011;33:165-170

26. Huth KC, Paschos E, Hajek-Al-Khatar N, Hollweck R, Crispin A, Hickel R, Folwaczny M. Effectiveness of 4 pulpotomy techniques--randomized controlled trial. J Dent Res. 2005;84: 1144-1148

27. Parirokh M, Torabinejad $M$. Mineral trioxide aggregate: a comprehensive literature review--Part I: chemical, physical, and antibacterial properties. J Endod. 2010;36:16-27

28. Haghgoo R, Abbasi F. Treatment of Furcal Perforation of Primary Molars with ProRoot MTA versus Root MTA: A Laboratory Study. Iran Endod J. 2013;8:52-54 